\title{
Thermal Recycling of Waelz Oxide Using Concentrated Solar Energy
}

\author{
N. TZOUGANATOS, ${ }^{1}$ R. MATTER,${ }^{2}$ C. WIECKERT, ${ }^{1}$ \\ J. ANTREKOWITSCH, ${ }^{3}$ M. GAMROTH, ${ }^{4}$ and A. STEINFELD ${ }^{1,2,5}$ \\ 1.-Solar Technology Laboratory, Paul Scherrer Institute, 5232 Villigen, Switzerland. \\ 2.-Department of Mechanical and Process Engineering, ETH Zurich, 8092 Zurich, Switzerland. \\ 3.-Department of Metallurgy, Montan University, 8700 Leoben, Austria. 4.-Befesa Steel \\ Services GmbH, 47269 Duisburg, Germany. 5.—e-mail: aldo.steinfeld@ethz.ch
}

\begin{abstract}
The dominating $\mathrm{Zn}$ recycling process is the so-called Waelz process. Waelz oxide (WOX), containing 55-65\% $\mathrm{Zn}$ in oxidic form, is mainly derived from electric arc furnace dust produced during recycling of galvanized steel. After its wash treatment to separate off chlorides, WOX is used as feedstock along with $\mathrm{ZnS}$ concentrates for the electrolytic production of high-grade zinc. Novel and environmentally cleaner routes for the purification of WOX and the production of $\mathrm{Zn}$ are investigated using concentrated solar energy as the source of high-temperature process heat. The solar-driven clinkering of WOX and its carbothermal reduction were experimentally demonstrated using a $10 \mathrm{~kW}_{\text {th }}$ packed-bed solar reactor. Solar clinkering at above $1265^{\circ} \mathrm{C}$ reduced the amount of impurities below $0.1 \mathrm{wt} . \%$. Solar carbothermal reduction using biocharcoal as reducing agent in the $1170-1320^{\circ} \mathrm{C}$ range yielded $90 \mathrm{wt} . \% \mathrm{Zn}$.
\end{abstract}

\section{INTRODUCTION}

The extensive application of zinc as an anticorrosion agent for steel, increasing global steel production and recycling, and the lack of zinc concentrates are main drivers for the development of zinc recycling technologies. Galvanized steel structures are scrapped after their operational life span and new steel is recovered in electric arc furnaces (EAFs). This energy-intensive process results in the concomitant generation of 15$25 \mathrm{~kg}$ of EAF dust per ton of steel. EAF dust consists mainly of $\mathrm{Zn}\left(18-35\right.$ wt. $\%$ as $\mathrm{ZnO}, \mathrm{ZnS}$, and $\mathrm{ZnCl}_{2}$ ), Fe (30-40 wt.\% as Fe and Fe oxides), as well as $\mathrm{Ca}$ and $\mathrm{Si}$ compounds. It is categorized as a hazardous solid waste material. ${ }^{1,2}$ The majority of the EAF dust generated worldwide is disposed in hazardous waste storage and landfill sites, without taking advantage of the possibility of converting waste materials to valuable feedstock for processes in closed material cycles. High stabilization and disposal costs, limited storage space, and strict environmental regulations have, however, urged the need for increasing recycling of EAF dust by pyrometallurgical, ${ }^{3-6}$ hydrometallurgi$\mathrm{cal}^{7-9}$ and chemical separation processes. More than 95\% of the EAF dust recycling capacity is provided by pyrometallurgical processes, the dominating of which is the so-called Waelz process. ${ }^{4,5}$ The use of hightemperature solar process heat for this purpose has been previously proposed and experimentally demonstrated. ${ }^{10,11}$

In the Waelz process, EAF dust is fed continuously into a rotary kiln along with a carbonaceous reducing agent and a slag-forming sand or lime. The kiln is slightly inclined for enabling residence times of $6-9 \mathrm{~h}$. The charge is transformed at about $1200^{\circ} \mathrm{C}$ into the iron-rich Waelz slag (composed mainly of 35-45 wt.\% $\mathrm{Fe}, 17-25$ wt.\% $\mathrm{CaO}$, and 7-10 wt.\% $\mathrm{SiO}_{2}$ ) and Waelz oxide (WOX). ${ }^{1}$ The latter is produced upon the volatilization of the nonferrous components of the charge, mainly $\mathrm{Zn}$ and $\mathrm{Pb}$, during the carbothermal reduction and their subsequent oxidation in an air flow entering through the discharge end of the kiln. Under normal operating conditions, the process is autothermal. The crude WOX generated contains about $60-65 \% \mathrm{Zn}$, mainly in the form of $\mathrm{ZnO}$. In addition, chlorides (3-7 wt.\% $\mathrm{Cl}$ as $\mathrm{NaCl}, \mathrm{KCl}, \mathrm{CaCl}_{2}, \mathrm{ZnCl}_{2}, \mathrm{PbCl}_{2}, \mathrm{~Pb}(\mathrm{OH}) \mathrm{Cl}$ ) and fluorides $\left(0.05-0.2\right.$ wt.\% $\mathrm{F}$ as $\left.\mathrm{NaF}, \mathrm{KF}, \mathrm{CaF}_{2}\right)$ are accumulated. These compounds restrict the direct feeding of WOX to the primary Zn electrolytic production plant. Thus, the last unit of the Waelz process comprises washing for dehalogenation of 


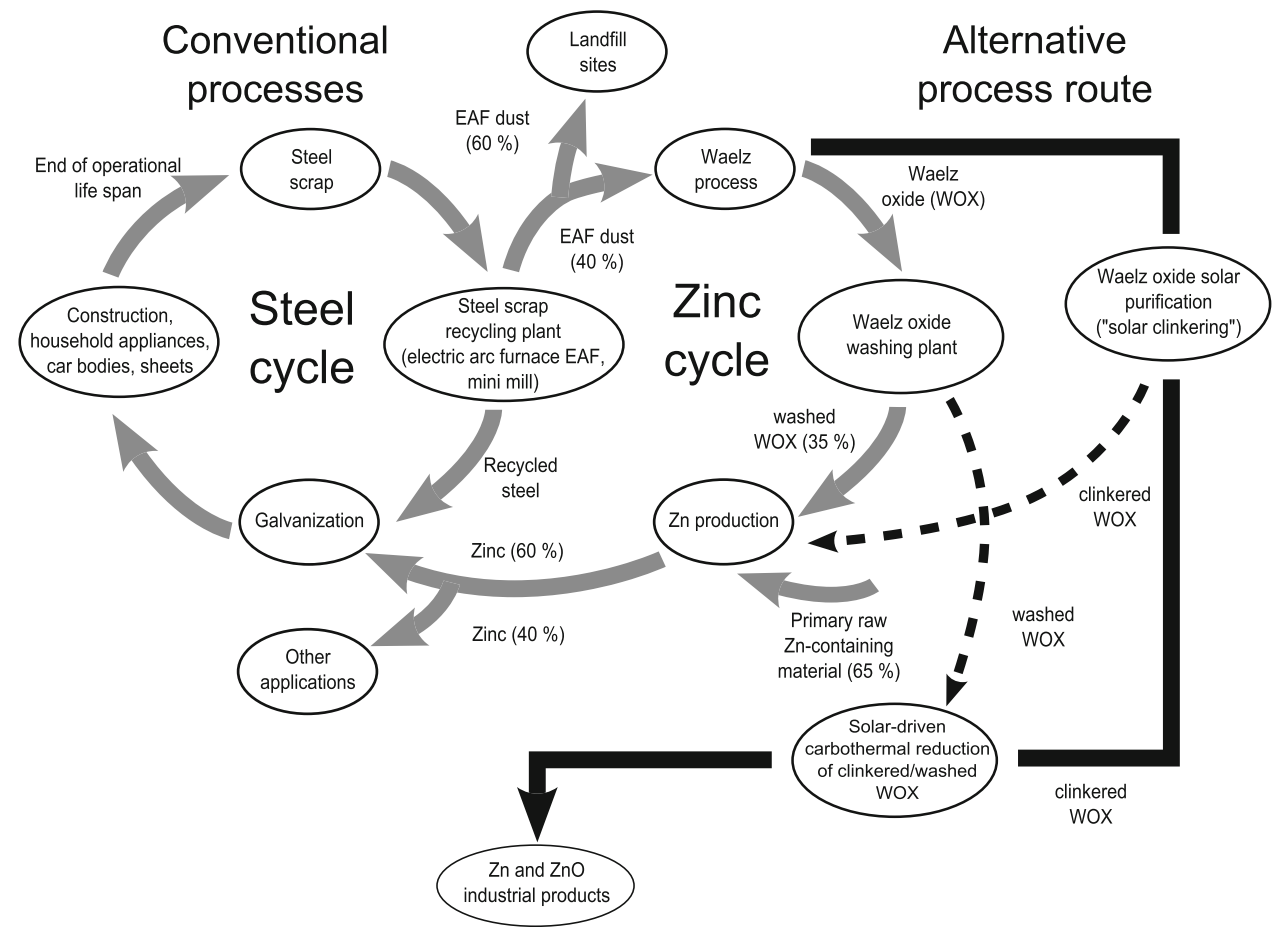

Fig. 1. Process flow diagram for the conventional steel and zinc industry and alternative routes using concentrated solar energy.

crude WOX. The end product, which constitutes a $\mathrm{Zn}$ concentrate (65-68 wt.\% $\mathrm{Zn}$ ), with chlorine and fluorine contents below 0.1 wt.\% and 0.15 wt. $\%$, respectively, is then obtained upon leaching of WOX. ${ }^{12}$ Washed WOX enters the Zn cycle as an input feedstock together with $\mathrm{ZnS}$ from ores. The effluent, containing the dissolved components, can be either released as wastewater after its further treatment to comply with the water pollution emissions (e.g., precipitation of heavy metals and neutralization) or crystallized in an evaporationcrystallization unit.

In this article, alternative cleaner process routes for the purification of WOX and the carbothermal production of $\mathrm{Zn}$ are investigated using concentrated solar energy to drive the highly endothermic reactions, as depicted in Fig. 1 . The first process considered is the solar-driven thermal purification of crude WOX via volatilization at temperatures in the range of $1000-1285^{\circ} \mathrm{C}$-referred as "solar clinkering"- to yield clinkered WOX, which has higher $\mathrm{Zn}$ content than washed WOX (>80 wt.\% $\mathrm{ZnO}$ ) and can be used as feedstock for the carbothermal production of zinc. The second process considered is the solar-driven carbothermal reduction of clinkered WOX. Biomass is the preferred reducing agent for a $\mathrm{CO}_{2}$-neutral process and for a high fraction of solar energy to be stored in $\mathrm{Zn} .{ }^{13}$ The simplified net reaction can be described by:

$$
\begin{gathered}
\mathrm{ZnO}(\mathrm{s})+\mathrm{C}(\mathrm{s})=\mathrm{Zn}(\mathrm{g})+\mathrm{CO} \\
\Delta H_{298 \mathrm{~K}}^{\circ}=239.9 \mathrm{~kJ} \mathrm{~mol}^{-1}
\end{gathered}
$$

The predominant reaction route is via the solid-gas reaction ${ }^{14}$ :

$$
\begin{gathered}
\mathrm{ZnO}(\mathrm{s})+\mathrm{CO}=\mathrm{Zn}(\mathrm{g})+\mathrm{CO}_{2} \\
\Delta H_{298 \mathrm{~K}}^{\circ}=67.5 \mathrm{~kJ} \mathrm{~mol}^{-1}
\end{gathered}
$$

where $\mathrm{CO}$ is formed by the Boudouard equilibrium:

$$
\mathrm{CO}_{2}+\mathrm{C}(\mathrm{s})=2 \mathrm{CO} \quad \Delta H_{298 \mathrm{~K}}^{\circ}=172.4 \mathrm{~kJ} \mathrm{~mol}^{-1} \text {. }
$$

Besides its wide industrial application as material commodity, $\mathrm{Zn}$ can be used as a fuel in $\mathrm{Zn}$-air batteries ${ }^{15,16}$ or reacted with $\mathrm{H}_{2} \mathrm{O}$ and $\mathrm{CO}_{2}$ to form highpurity $\mathrm{H}_{2}{ }^{17-21}$ and $\mathrm{CO}_{2}{ }^{22}$ which are precursors for synthetic liquid fuels. ${ }^{23,24}$ Alternatively, $\mathrm{Zn}$ can be oxidized at the solar reactor exit for the production of high-purity $\mathrm{ZnO}$. The technical feasibility of a packed-bed solar reactor is experimentally investigated for performing both processes: the solar clinkering of WOX and the solar carbothermal reduction of clinkered WOX. In the solar clinkering experiments, the focus is in elucidating the influence of temperature and irradiation time on the composition of clinkered WOX. In the carbothermal reduction experiments, the main focus lies on the $\mathrm{Zn}$ production rate and $\mathrm{Zn}$ content in the condensed product.

\section{EXPERIMENTAL}

\section{Solar Concentrating System}

Experimentation was carried out at Paul Scherrer Institute's high-flux solar simulator (HFSS). ${ }^{25}$ This 
research facility comprises an array of ten high-pressure Xe arcs close coupled with ellipsoidal specular reflectors and provides up to $50 \mathrm{~kW}_{\mathrm{th}}$ of thermal radiative power at peak radiative fluxes of 11,000 suns $\left(1 \mathrm{sun}=1 \mathrm{~kW} / \mathrm{m}^{2}\right)$. Thus, solar receivers and reactors can be tested under the same radiative heat transfer characteristics of highly concentrating solar systems. Power flux intensities can be regulated by the number of arcs in operation, the relative position of the test target to the focal plane, and the Venetian blind-type shutter located between the arcs and the solar reactor. The input solar radiative power and flux distributions are measured optically with a calibrated charge-coupled device (CCD) camera on an $\mathrm{Al}_{2} \mathrm{O}_{3}$-plasma coated Lambertian target with an accuracy of $10 \%$. A watercooled, Al-polished $45^{\circ}$-deflection mirror is used for redirecting the incoming horizontal beam into a vertical beam entering a three-dimensional compound parabolic concentrator (CPC). ${ }^{26}$ The CPC, of $80 \mathrm{~mm}$ diameter entrance and $65 \mathrm{~mm}$-diameter exit, is incorporated at the reactor's aperture to boost the incoming radiation flux intensity and decrease reradiation losses through a smaller aperture size.

\section{Solar Reactor}

The solar reactor configuration is shown schematically in Fig. 2. It is specifically designed for beamdown operation as obtained through a Cassegrain optical configuration that makes use of a hyperbolic reflector at the top of a solar tower to redirect sunlight collected by a heliostat field to a receiver located at ground level. ${ }^{27}$ It consists of two cavities in series, separated by a $170 \mathrm{~mm}$-diameter $5 \mathrm{~mm}$-thick SiCcoated graphite plate. The upper cavity is subjected to concentrated solar irradiation entering through a
$65 \mathrm{~mm}$-diameter circular aperture with a $2 \mathrm{~mm}$ thick quartz window. The lower cavity is an octagonal, $135 \mathrm{~mm}$-diameter, $170 \mathrm{~mm}$-high enclosure that serves as the reaction chamber and contains a packed bed of solid reactants. With this arrangement, concentrated solar radiation is efficiently absorbed by the upper cavity, reradiated by the hot separation plate toward the lower cavity, and absorbed by the top of the packed bed. An inert carrier gas enters the upper cavity, cools the window, and flows through small gaps around the separation plate into the lower cavity to prevent reaction gas from reaching the quartz window. The lower cavity is also flushed with an inert carrier gas entering the reactor below the separation plate. The gaseous products are swept out through a $50 \mathrm{~mm}$-diameter outlet port located on the lateral walls of the lower cavity, above the packed bed. The walls of the lower cavity are lined with $8 \mathrm{~mm}$-thick $\mathrm{SiC}$ plates to prevent the diffusion of condensable gaseous products into the insulation material. Both cavities are well insulated to reduce heat conduction losses. The two-cavity reactor configuration enables the protection of the quartz window against condensable gases and particle depositions by the separation plate, and thus it eliminates a major problem encountered in windowed reactors. Generic design guidelines for maximization of the thermal efficiency of the two-cavity reactor configuration are provided based on radiation heat transfer analyses. 28,29

\section{Experimental Setup}

A flow diagram of the experimental setup is shown in Fig. 3. Inert gas $\left(\mathrm{N}_{2}\right)$ mass flow rates are controlled by Bronkhorst flow meters (EL-flow

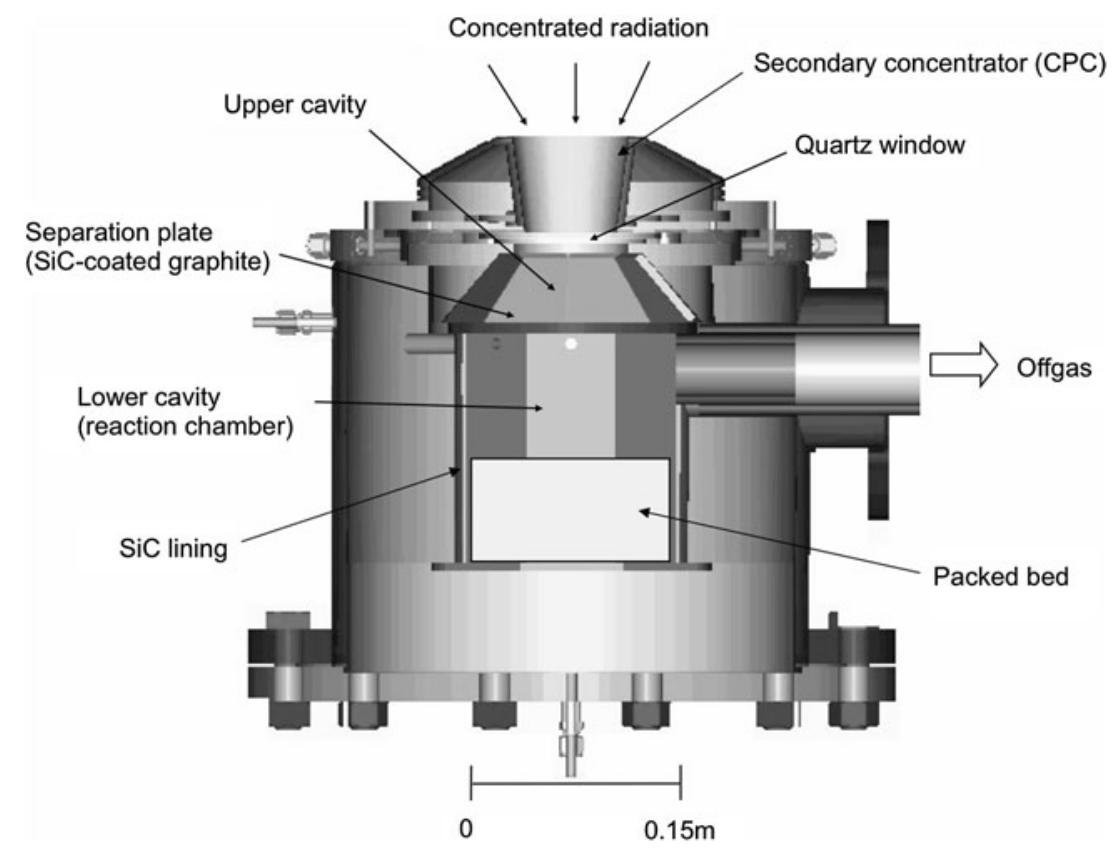

Fig. 2. Schematic of the $10 \mathrm{~kW}_{\text {th }}$ packed-bed solar reactor. 


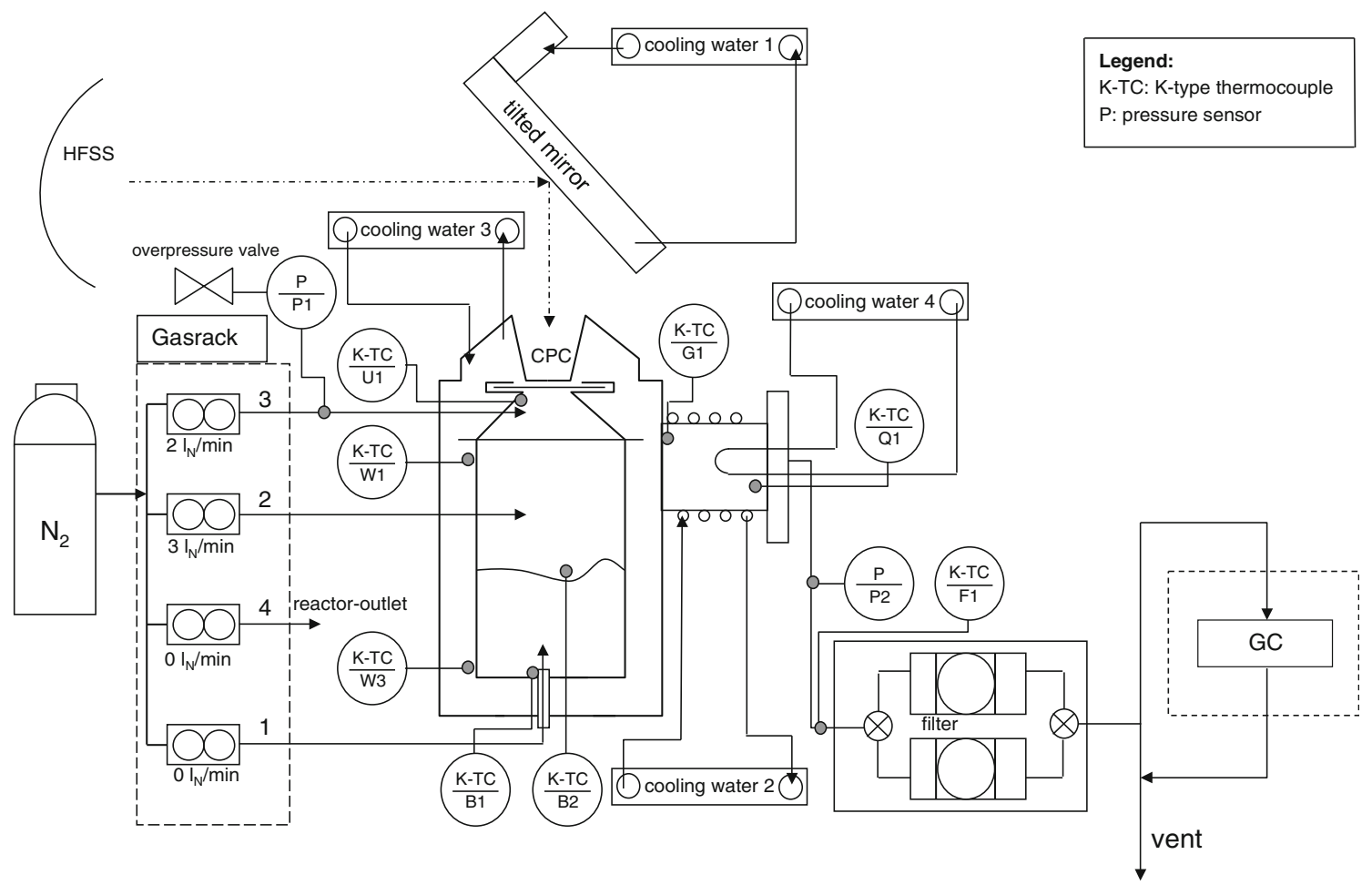

Fig. 3. Flow diagram of the experimental setup comprising the solar concentrating system, the solar reactor, the off-gas system, and the diagnostic instrumentation.

series). Two and three $L_{\mathrm{N}} \min ^{-1}\left(L_{\mathrm{N}}\right.$ means liters at normal conditions; mass flow rates are calculated at $273 \mathrm{~K}$ and $1 \mathrm{bar}$ ) enter the upper and lower cavity, respectively. After exiting the reactor, the carrier gas and the gaseous products flow through a water-cooled condenser where part of the condensable products deposit before passing through a filtering system. The composition of the noncondensable product gases behind the filter is analyzed online by gas chromatography (Micro GC M200, $0.01 \mathrm{~Hz}$ sampling rate; Agilent Technologies, Santa Clara, CA). All experiments were performed at slightly above ambient pressure, with relative pressures of $\sim 5-10$ mbar. The pressure is monitored online in the upper cavity of the reactor (P1) and upstream of the filter unit (P2). A pressure relief valve opening at a pressure of $150 \mathrm{mbar}$ prevents damage of the quartz window in the case of clogging of the off-gas system. Packed-bed, reaction chamber walls, and off-gas temperatures are measured at eight locations by type-K thermocouples. Temperatures at the top $\left(T_{\mathrm{B} 2}\right)$ and bottom of the packed bed $\left(T_{\mathrm{B} 1}\right)$ provide the temperature gradient across the bed. For the carbothermal reduction, $T_{\mathrm{B} 2}-T_{\mathrm{B} 1}$ indicates the remaining unreacted material and ash. The temperatures of the separation plate $\left(T_{\mathrm{U} 1}\right)$ and of the inner $\mathrm{SiC}$ lining approximately $8 \mathrm{~mm}$ below the separation plate $\left(T_{\mathrm{w} 1}\right)$ are representative for the upper and lower cavity, respectively.

\section{Materials}

The crude and washed WOX used for the experiments originated from the Waelz kiln at Befesa Freiberg, Germany. Washed WOX was derived in the washing plant upon a three-step leaching of crude WOX. The elemental composition in \% (w/w) of a dried sample is listed in Table I.

For crude WOX, $\mathrm{Zn}, \mathrm{Pb}$, and $\mathrm{Fe}$ were present primarily in their oxidized state with $\mathrm{ZnO}$ being the main constituent in the range $71-77 \mathrm{wt} . \%,{ }^{30}$ whereas the remaining components were in the form of chlorides $\left(\mathrm{ZnCl}_{2}, \mathrm{PbCl}_{2}, \mathrm{NaCl}\right.$, and $\left.\mathrm{KCl}\right)$ and sulfates. For washed WOX, the $\mathrm{ZnO}$ content varied in the range of 83-87 wt.\%. The pronounced decrease in the $\mathrm{K}, \mathrm{Na}$, and $\mathrm{Cl}$ contents in washed WOX is attributed to the depletion of chlorine by washing, which generates $\mathrm{Zn}-, \mathrm{Pb}-$, and Fe-enriched mixtures. The water content of the crude and washed WOX determined by drying at $105^{\circ} \mathrm{C}$ for $24 \mathrm{~h}$ was $1.1 \mathrm{wt} . \%$ and $12.6 \mathrm{wt} . \%$, respectively. To ensure well-characterized properties and precise $\mathrm{ZnO}: \mathrm{C}$ molar ratios in the starting reacting mixture, commercial ZnO (Alfa Aesar, Ward Hill, MA; 011558, purity: $99.0 \%$ min, mean particle size $44 \mu \mathrm{m}$ ) was used as feedstock in several carbothermal reduction runs for comparison with runs using crude, washed, and clinkered WOX as feedstock. Beech charcoal gravel (proFagus, Bodenfelde, Germany; carbon content $83 \mathrm{wt} . \%$, particle size $0.5-1.0 \mathrm{~mm}$ ) was used 
Table I. Elemental composition of crude and washed WOX (dry basis)

\begin{tabular}{lccc}
\hline Element & & Crude WOX (wt.\%) & Washed WOX (wt.\%) \\
\cline { 1 - 1 } $\mathrm{Zn}$ & 60.05 & 3.64 & 68.30 \\
$\mathrm{~Pb}$ & 5.57 & 5.17 \\
$\mathrm{Cl}$ & 3.49 & 0.43 \\
$\mathrm{~K}$ & 1.62 & 0.09 \\
$\mathrm{Na}$ & 1.64 & 0.26 \\
$\mathrm{Fe}$ & 1.33 & 2.64 \\
$\mathrm{C}$ & 0.58 & 1.39 \\
$\mathrm{~S}$ & 0.12 & 0.16 \\
$\mathrm{~F}$ & & 0.20 \\
\hline
\end{tabular}

Oxygen is complementary to $100 \%$.

Table II. Chemical composition of beech charcoal ash

\begin{tabular}{lr}
\hline Component & Wt.\% \\
$\mathrm{CaO}$ & 44.81 \\
$\mathrm{SiO}$ & \\
$\mathrm{MgO}$ & 20.00 \\
$\mathrm{~K}_{2} \mathrm{O}$ & 14.44 \\
$\mathrm{SO}_{3}$ & 4.36 \\
$\mathrm{MnO}$ & 3.52 \\
$\mathrm{Al}_{2} \mathrm{O}_{3}$ & 3.01 \\
$\mathrm{FeO}$ & 2.43 \\
$\mathrm{TiO}_{2}$ & 2.20 \\
$\mathrm{Na} \mathrm{Zn}_{2}$ & 1.29 \\
$\mathrm{Cu}$ & 0.94 \\
$\mathrm{Ni}$ & 0.10 \\
$\mathrm{Cl}$ & 0.05 \\
\end{tabular}

as reducing agent because it is a widely available biogenic material suitable for the $\mathrm{CO}_{2}$-neutral solar carbothermal reduction of $\mathrm{ZnO}{ }^{31}$ It contained 83 wt.\% C, 9.74 wt.\% O, 3.02 wt.\% H, 0.38 wt.\% N, 0.01 wt.\% S, and 2.2 wt.\% ash. The ash composition is listed in Table II. Softening and fusion occur at $1210^{\circ} \mathrm{C}$ and $1415^{\circ} \mathrm{C}$, respectively. ${ }^{31}$

The composition of raw materials was analyzed by x-ray powder diffraction (XRD; Phillips, Almelo, the Netherlands; XPert MPD/DY636, $\mathrm{Cu} \mathrm{K} \alpha, \lambda=$ $1.540598 \AA, 2 \theta=20^{\circ}-90^{\circ}$, step size $0.05^{\circ}$, scan speed $0.01 \%$ s) and their morphology was examined by scanning electron microscopy (SEM, SmartSEM, Carl Zeiss Supra 55VP; Carl Zeiss, Oberkochen, Germany). As expected, $\mathrm{ZnO}, \mathrm{PbO}, \mathrm{Fe}_{2} \mathrm{O}_{3}, \mathrm{NaCl}$ and $\mathrm{KCl}$ were the dominating phases in crude WOX. No $\mathrm{NaCl}$ and $\mathrm{KCl}$ were detected for the washed WOX. The SEM pictures of the crude and washed WOX, commercial $\mathrm{ZnO}$, and beech charcoal are shown in Fig. 4. The commercial $\mathrm{ZnO}$ and the majority of the crude and washed WOX particles exhibited a wurtzite crystal structure: a hexagonal lattice consisting of two interconnecting sublattices of $\mathrm{Zn}^{2+}$ and $\mathrm{O}^{2-}$, which allow the tetrahedral coordination of $\mathrm{Zn}$ and $\mathrm{O}$ atoms. All $\mathrm{ZnO}$ sources comprised highly agglomerated grains with negligible intraparticle porosity, indicating that the porosity can be attributed mainly to the interparticle void spaces. Crude and washed WOX also contained fine needles and sponge-like structures. Beech charcoal was highly branched and contained tubular pores.

\section{Experimental Procedure}

For the solar clinkering experiments, batches of crude WOX were loaded on a crucible made of heatresistant austenitic stainless steel (Böhler H525, 1.4841; Böhler, Kapfenberg, Germany) resulting in a $\sim 40 \mathrm{~mm}$-thick porous bed. The upper and lower cavities were initially flushed with $\mathrm{N}_{2}$. After ensuring $\mathrm{O}_{2}$ concentration below $300 \mathrm{ppm}$, the HFSS was ignited and the shutter opening was increased stepwise at a $10 \%$ increment every $3 \mathrm{~min}$, allowing the gradual heating of the packed bed to the desired temperature $T_{\mathrm{B} 1}$. This temperature was maintained constant for different time intervals $(0$, 15,30 , and $75 \mathrm{~min}$ ) depending on the goal of each experiment. At the end, the shutter was closed and the HFSS was switched off. The carrier gas flow was maintained until the cavity cooled down. The same procedure was followed for the carbothermal reduction experiments. $\mathrm{ZnO}: \mathrm{C}$ molar ratios of reactants ranged between 1:0.8 and 1:1.25. The values listed in Table I were used for the calculation of the molar ratios when crude or washed WOX were used as feedstock. The initial packed bed height was $\sim 40 \mathrm{~mm}$. $T_{\mathrm{B} 1}$ was kept constant until the $\mathrm{CO}$ and $\mathrm{CO}_{2}$ concentrations approached zero, indicating that the reaction neared completion. The $\mathrm{Zn}$ production rate was calculated from the oxygen balance in $\mathrm{CO}$ and $\mathrm{CO}_{2}$. This calculation slightly overestimated the amount of $\mathrm{Zn}$ produced because it did not account for the oxygen content in charcoal and impurity oxides $\left(\mathrm{PbO}, \mathrm{Fe}_{2} \mathrm{O}_{3}\right.$, etc.) present in crude, washed, or clinkered WOX, a fraction of which may end up in $\mathrm{CO}$ or $\mathrm{CO}_{2}$ as well. Products were analyzed for their $\mathrm{Zn}, \mathrm{Pb}, \mathrm{Cl}, \mathrm{F}, \mathrm{K}, \mathrm{Na}$, and $\mathrm{Fe}$ content by elemental analysis, for their phase composition by XRD, and for their morphology by SEM.

\section{RESULTS AND DISCUSSION}

\section{Solar Clinkering}

Fifteen experimental runs were carried out with the solar radiative power input in the range 4.1$4.85 \mathrm{~kW}_{\text {th }}$. Under approximately steady-state conditions, the packed-bed top $\left(T_{\mathrm{B} 2}\right)$ and bottom $\left(T_{\mathrm{B} 1}\right)$ temperatures reached $1050-1310^{\circ} \mathrm{C}$ and $1000-$ $1285^{\circ} \mathrm{C}$, respectively. A representative run with $470 \mathrm{~g}$ of crude WOX is shown in Fig. 5. After the stepwise increase of the radiative power input to $3.2 \mathrm{~kW}_{\text {th }}$ within the first $18 \mathrm{~min}$, the upper cavity temperature $\left(T_{\mathrm{U} 1}\right)$ increased to $840^{\circ} \mathrm{C}$ and the one at the top of the packed bed $\left(T_{\mathrm{B} 2}\right)$ to $420^{\circ} \mathrm{C}$. Small 

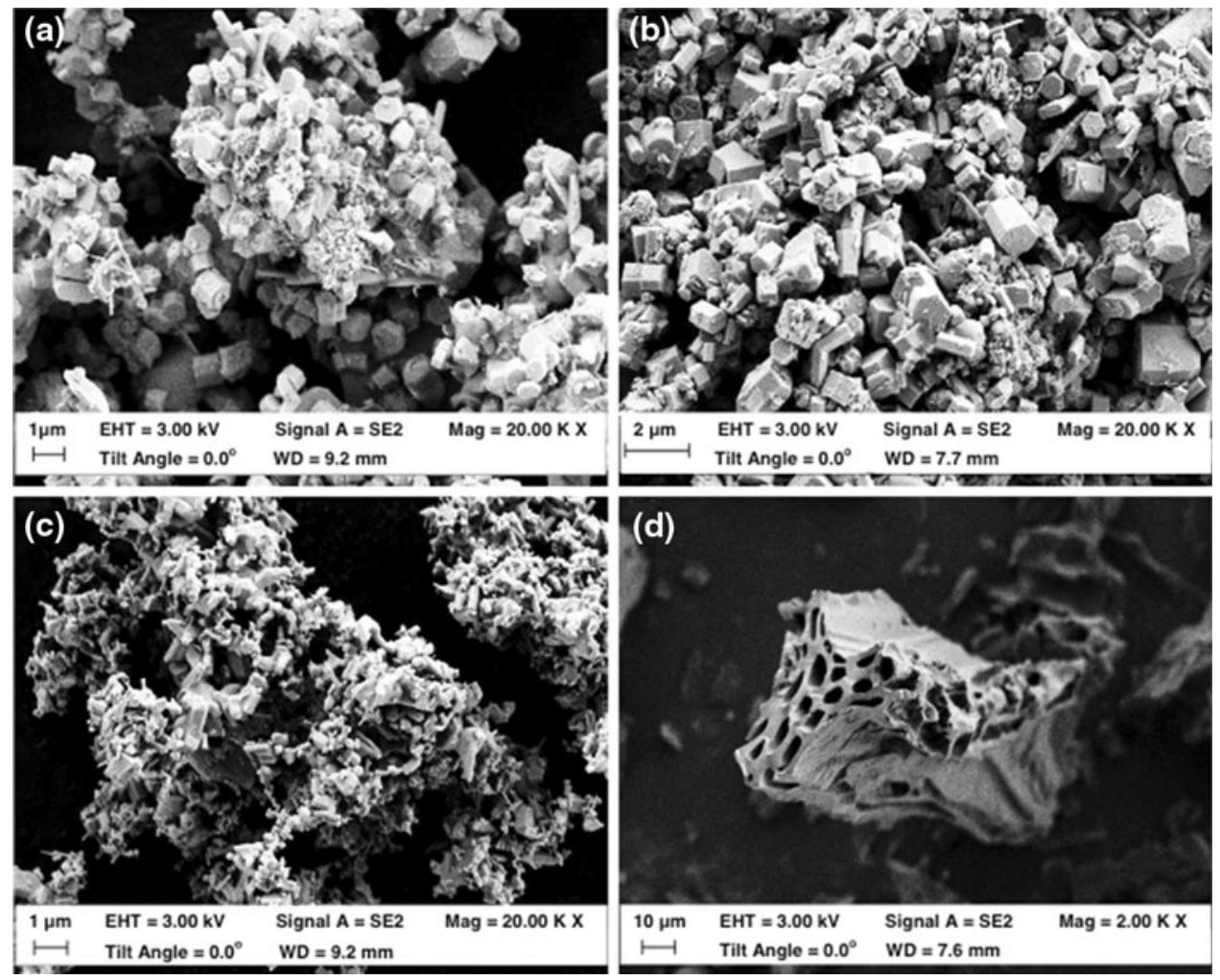

Fig. 4. SEM pictures of: (a) crude WOX, (b) washed WOX, (c) commercial ZnO, and (d) beech charcoal.

amounts of $\mathrm{CO}_{2}$ were attributed to residual oxygen. The full opening of the shutter after 27 min was immediately followed by the formation of higher $\mathrm{CO}_{2}$ amounts. After $40 \mathrm{~min}$, the reaction proceeded at higher rates once $T_{\mathrm{B} 2}$ and $T_{\mathrm{B} 1}$ reached $965^{\circ} \mathrm{C}$ and $360^{\circ} \mathrm{C}$, respectively. The temperature gradient across the packed bed decreased with time due to the shrinkage of the bed; a temperature difference of $\sim 90^{\circ} \mathrm{C} \quad\left(T_{\mathrm{B} 2}=1310^{\circ} \mathrm{C}\right.$ and $\left.T_{\mathrm{B} 1}=1220^{\circ} \mathrm{C}\right)$ was observed at steady-state conditions. The gas flow rate of $\mathrm{CO}_{2}$ reached a maximum of $0.012 \mathrm{~mol} / \mathrm{min}$ after 55 min, while $\mathrm{CO}$ and $\mathrm{H}_{2}$ were also detected in the off-gas flow. $\mathrm{CO}$ became the predominant component of the off-gas at higher temperatures, consistent with the Boudouard equilibrium (Eq. 3). $T_{\mathrm{B} 1}$ stabilized after 100 min and the evolution of $\mathrm{CO}$ and $\mathrm{CO}_{2}$ ceased, indicating the consumption of the carbon contained in the crude WOX. The desired $T_{\mathrm{B} 1}$ of $1220^{\circ} \mathrm{C}$ was reached after $130 \mathrm{~min}$ and maintained during $30 \mathrm{~min}$ before turning off the HFSS. The clinkered WOX collected from the crucible contained 68.1 wt. $\% \mathrm{Zn}, 0.92$ wt. $\% \mathrm{Cl}$, and 0.79 wt.\% $\mathrm{Pb}$. Other elements present in lower percentage were $\mathrm{Fe}$ and $\mathrm{Ca}$. The effectiveness of solar clinkering in terms of the $\mathrm{Zn}$ content was comparable to the one acquired by the industrial washing process (see washed WOX in Table I). The decrease of $\mathrm{Pb}$ content was even better. $\mathrm{ZnO}, \mathrm{Fe}_{2} \mathrm{O}_{3}, \mathrm{MnO}, \mathrm{PbO}$, and $\mathrm{KCl}$ were detected by XRD analysis, while no $\mathrm{NaCl}$ peaks were found. A representative SEM picture of clinkered WOX that underwent partial melting is

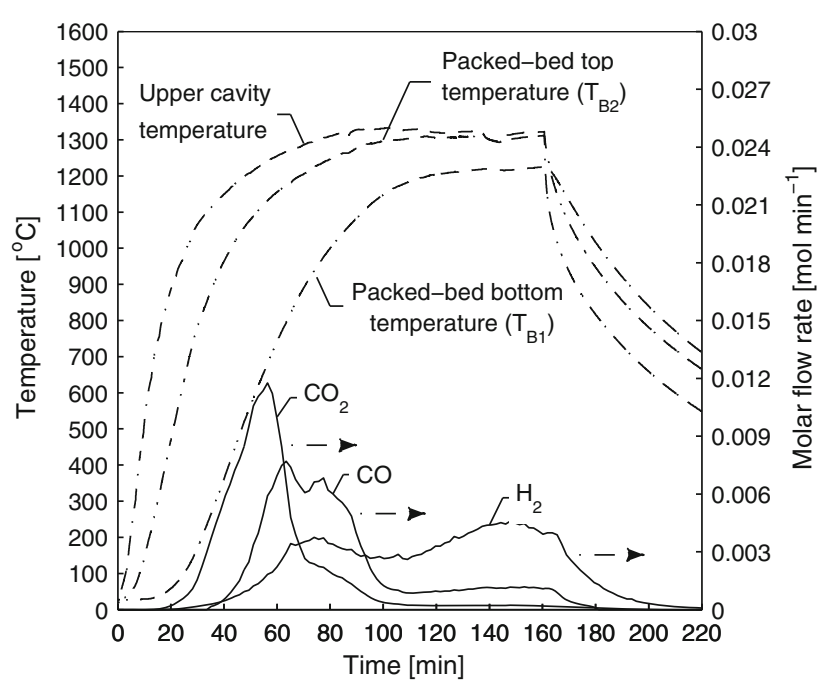

Fig. 5. Solar reactor temperatures and molar flow rates of $\mathrm{CO}, \mathrm{CO}_{2}$, and $\mathrm{H}_{2}$ during a representative solar clinkering experiment with $470 \mathrm{~g}$ of crude WOX.

shown in Fig. 6. Condensed by-products were deposited on the condenser walls, the cooling finger, the outlet pipes, and the filter. XRD analysis revealed the presence of $\mathrm{ZnO}, \mathrm{Zn}, \mathrm{NaCl}, \mathrm{KCl}, \mathrm{PbO}$, and $\mathrm{Pb}$. $\mathrm{Zn}$ was presumably formed by the reduction of $\mathrm{ZnO}$ with the small amount of carbon contained in crude WOX $(\sim 1.3$ wt.\%). Films of $\mathrm{ZnO}$ were formed on the $\mathrm{Zn}$ surface upon exposure to air. 


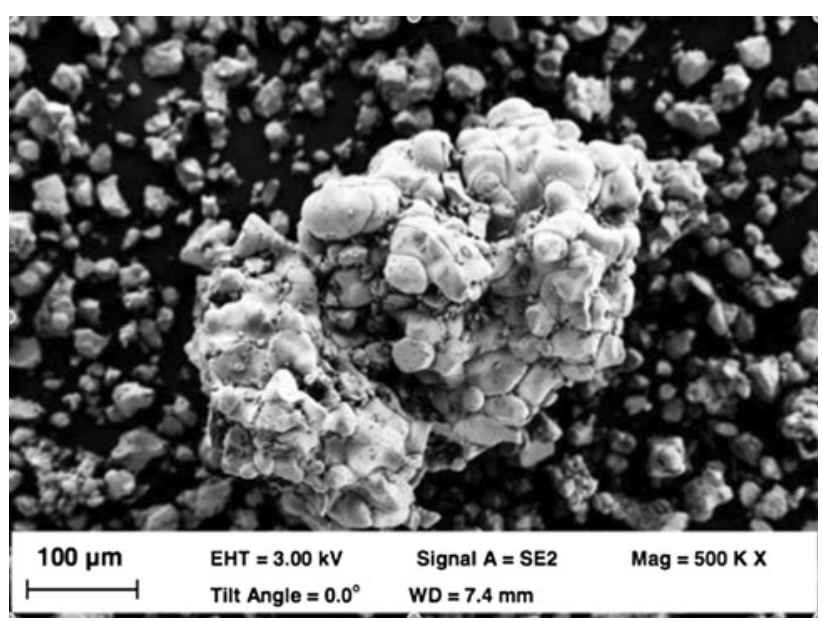

Fig. 6. SEM of solar-clinkered WOX.

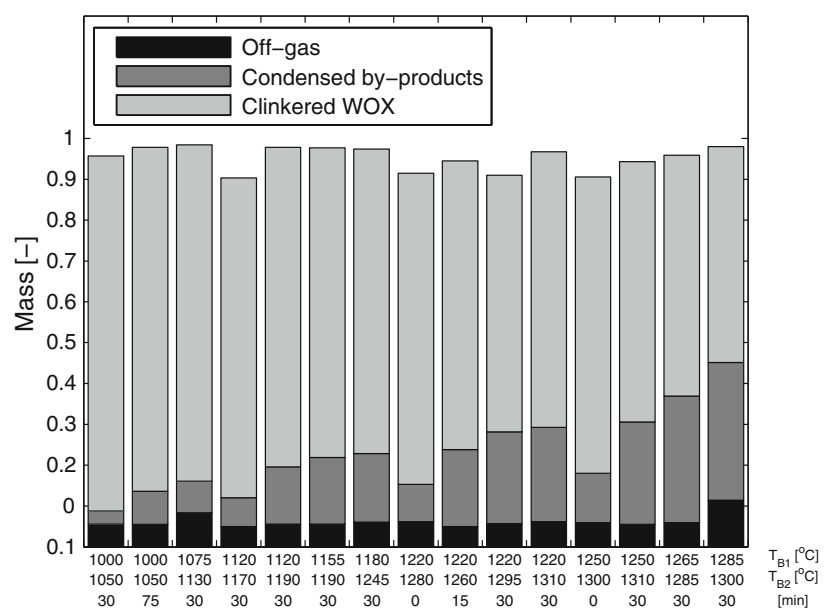

Fig. 7. Normalized mass balance for the solar clinkering experiments. The nominal temperatures at the bottom $\left(T_{\mathrm{B} 1}\right)$ and top $\left(T_{\mathrm{B} 2}\right)$ of the packed bed and the irradiation time period at this temperature level are indicated in the $x$ axis.

$\mathrm{NaCl}, \mathrm{KCl}$, and $\mathrm{PbO}$ evaporated at the temperatures investigated, thus decreasing the $\mathrm{Cl}$ and $\mathrm{Pb}$ content of the processed crude WOX. The formation of $\mathrm{Pb}$ can be attributed to the reduction of $\mathrm{PbO}$ with $\mathrm{CO}$, either at the surface of the off-gas system components or during condensation in the aerosol.

The normalized mass balance is shown in Fig. 7 for all 15 solar clinkering experiments. Also indicated are the nominal temperatures at the bottom $\left(T_{\mathrm{B} 1}\right)$ and top $\left(T_{\mathrm{B} 2}\right)$ of the packed bed and the irradiation time period at this temperature level. The mass balance is satisfactorily closed for most experiments. Deviations from $100 \%$ are partially attributed to the discrete measurements of the gas composition $\left(0.01 \mathrm{~Hz}\right.$ sampling rate). $\mathrm{CO}, \mathrm{CO}_{2}$, and $\mathrm{H}_{2}$ accounted for $\sim 5-11 \%$ of the mass and were linked to the amount of carbon in crude WOX
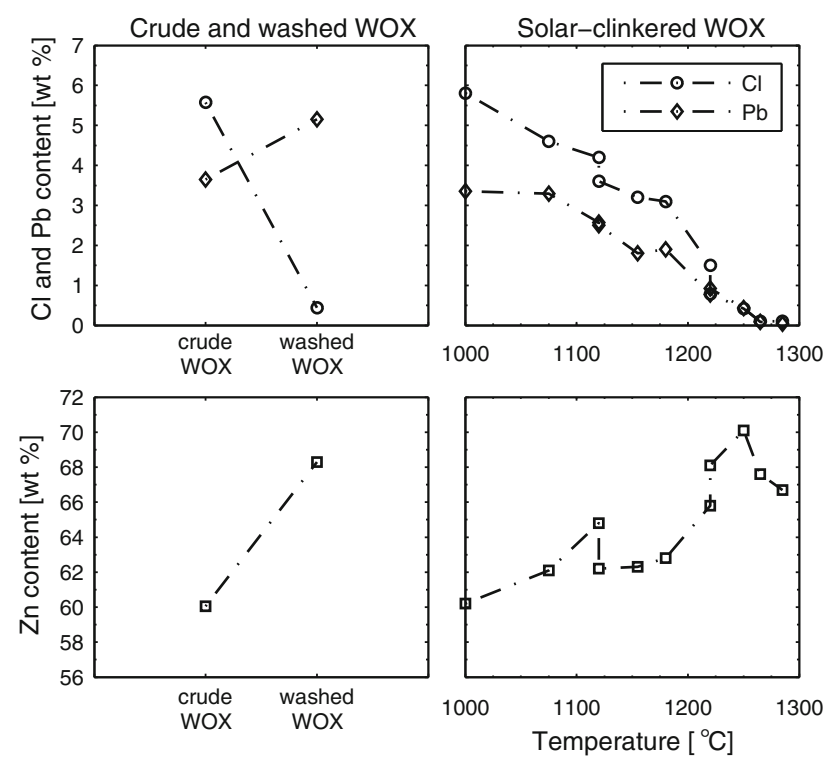

Fig. 8. $\mathrm{Zn}, \mathrm{Cl}$, and $\mathrm{Pb}$ content of crude, washed, and solar-clinkered WOX.

Table III. Boiling points of $\mathrm{Cl}$ and $\mathrm{Pb}$ compounds

\begin{tabular}{lc}
\hline Element/compound & Boiling point $\left({ }^{\circ} \mathbf{C}\right)$ \\
$\mathrm{ZnCl}_{2}$ & 732 \\
$\mathrm{PbCl}_{2}$ & 950 \\
$\mathrm{KCl}$ & 1413 \\
$\mathrm{NaCl}$ & 1465 \\
$\mathrm{PbO}$ & 1470 \\
$\mathrm{~Pb}$ & 1749 \\
\hline
\end{tabular}

( 1.3 wt.\%). Temperature had a profound effect on the amount of condensed by-products because of the nonlinear dependence of the vapor pressure with temperature, which favors vaporization from crude WOX. Larger amounts of condensed by-products were detected with increasing irradiation times, indicating that evaporation was not completed for the short tests. A comparison of the compositions of crude, washed, and solar-clinkered WOX with respect to the $\mathrm{Zn}, \mathrm{Cl}$, and $\mathrm{Pb}$ content is provided in Fig. 8. In this figure, the irradiation time period for solar clinkering was $30 \mathrm{~min}$. A notable decrease of $\mathrm{Cl}$ and $\mathrm{Pb}$ with increasing temperature was observed, which was accompanied by an increase in the $\mathrm{Zn}$ content. As $\mathrm{ZnCl}_{2}$ and $\mathrm{PbCl}_{2}$ exerted higher vapor pressures compared to other $\mathrm{Cl}$ and $\mathrm{Pb}$ compounds (see Table III), they were vaporized at lower temperatures. The volatilization of $\mathrm{KCl}, \mathrm{NaCl}, \mathrm{PbO}$, and $\mathrm{Pb}$ was favored with increasing temperature, leading to further purification of crude WOX. A Cl content of $0.42 \mathrm{wt} . \%$, comparable to that of washed WOX, was reached after $30 \mathrm{~min}$ irradiation at $T_{\mathrm{B} 1}=1250^{\circ} \mathrm{C}$. At $T_{\mathrm{B} 1}>1265^{\circ} \mathrm{C}$, the $\mathrm{Cl}$ content 


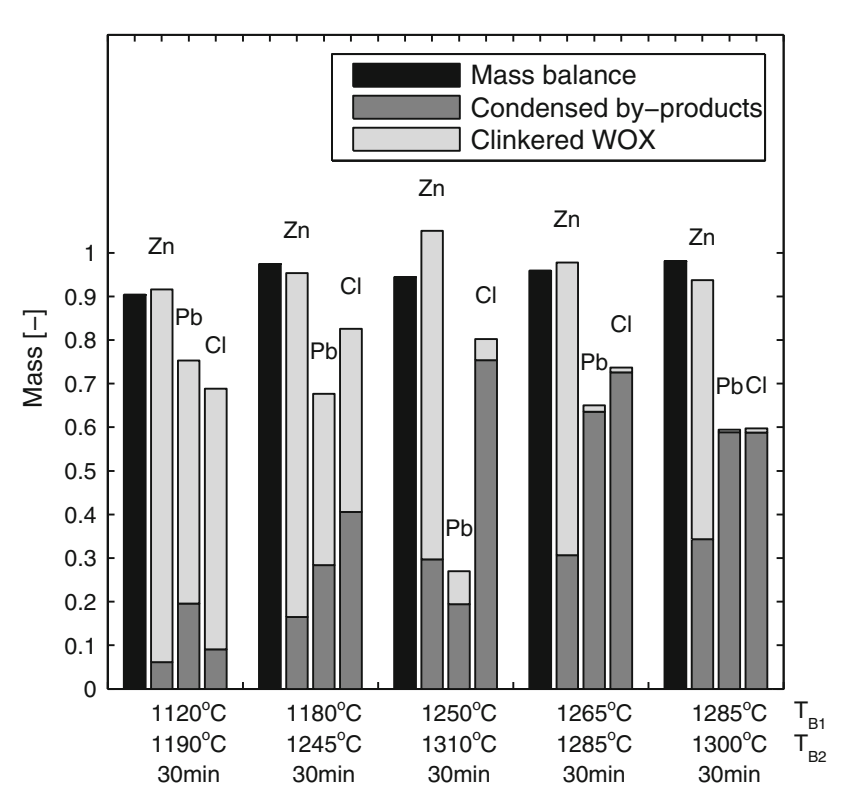

Fig. 9. Normalized mass and elemental $(\mathrm{Zn}, \mathrm{Pb}$, and $\mathrm{Cl})$ balances for five selected solar clinkering runs. The nominal temperatures at the bottom $\left(T_{\mathrm{B} 1}\right)$ and top $\left(T_{\mathrm{B} 2}\right)$ of the packed bed and the irradiation time period at this temperature level are indicated in the $x$ axis.

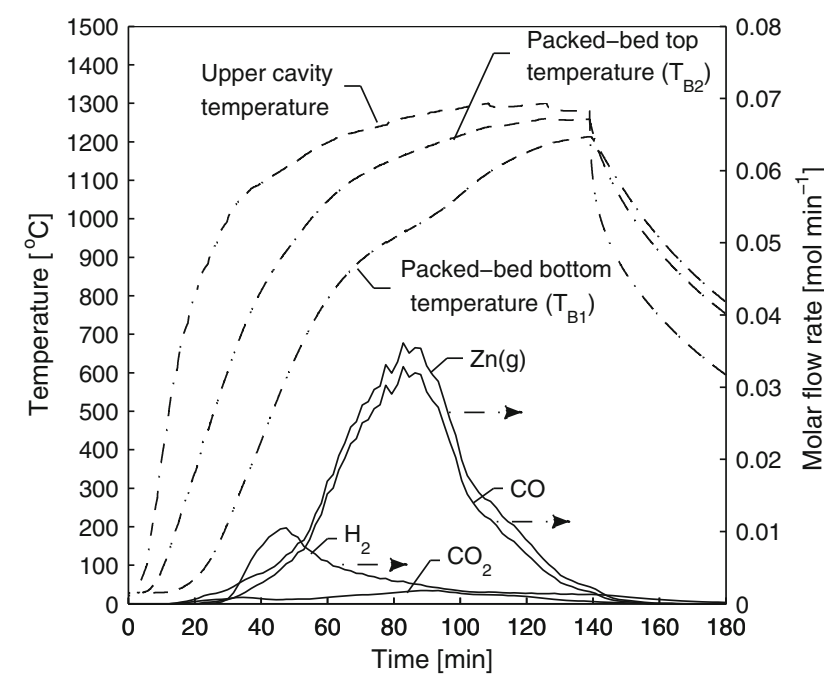

Fig. 10. Solar reactor temperatures and molar flow rates of $\mathrm{Zn}, \mathrm{CO}$, $\mathrm{CO}_{2}$, and $\mathrm{H}_{2}$ during a representative experimental run for the solardriven carbothermal reduction of clinkered WOX, using $240 \mathrm{~g}$ of reactants with a $\mathrm{ZnO}: \mathrm{C}$ molar ratio of 1:0.86.

further decreased below $0.1 \%$. In contrast to the conventional WOX washing process, very low residual $\mathrm{Pb}$ contents of 0.09 wt.\% and 0.04 wt.\% were obtained by solar clinkering at $T_{\mathrm{B} 1}=1265^{\circ} \mathrm{C}$ and $1285^{\circ} \mathrm{C}$, respectively. This effective purification is of particular importance because it enables the direct neutralization of the product in the Jarosite step of the primary $\mathrm{Zn}$ production cycle ${ }^{32}$ without the need to pass it through the roaster. The clinkered WOX and condensed by-products were analyzed for their $\mathrm{Zn}, \mathrm{Cl}$, and $\mathrm{Pb}$ content. The

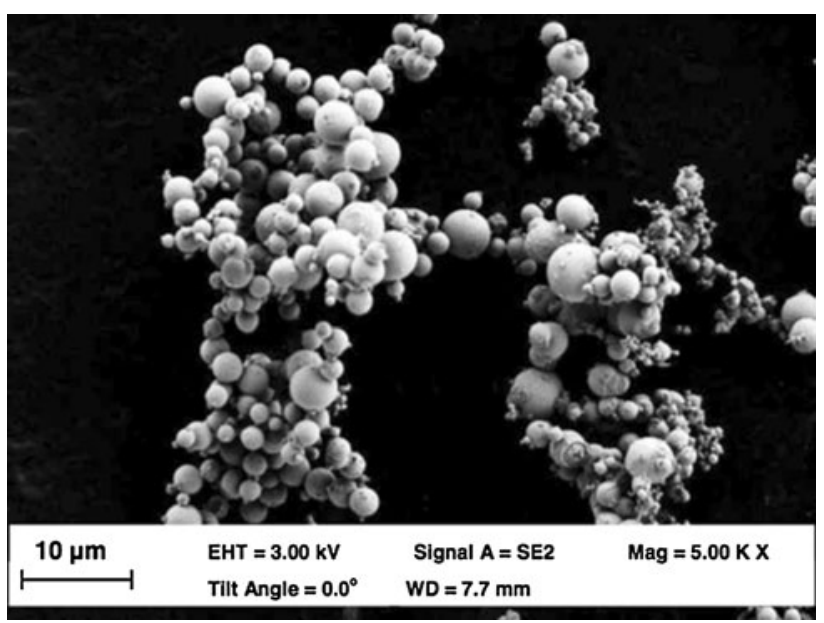

Fig. 11. SEM of condensed products from the solar carbothermal reduction.

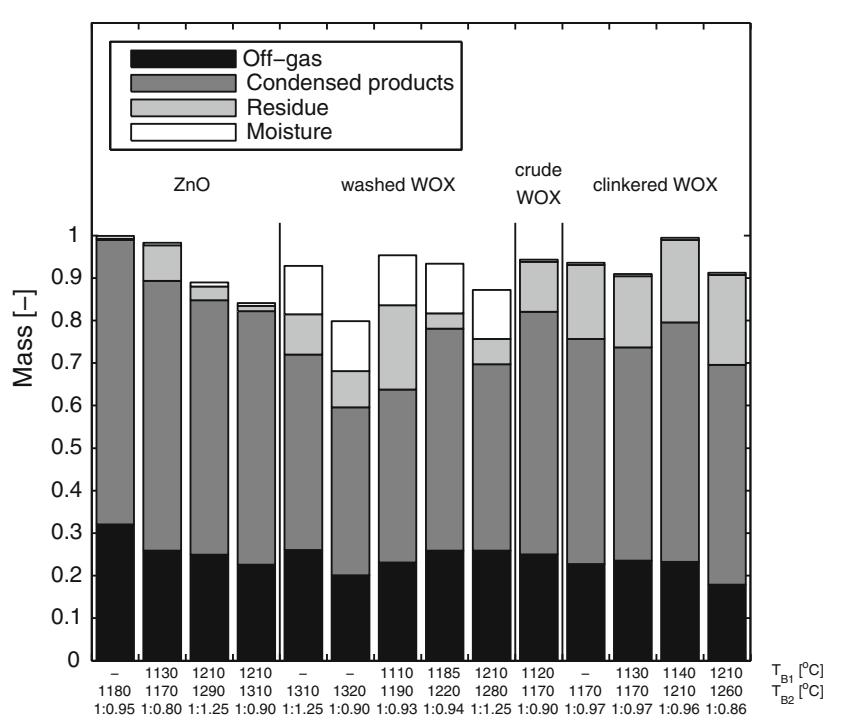

Fig. 12. Normalized mass balance of the solar carbothermal reduction experiments with different feedstock. The nominal temperatures at the bottom $\left(T_{\mathrm{B} 1}\right)$ and top $\left(T_{\mathrm{B} 2}\right)$ of the packed bed and the $\mathrm{ZnO}: \mathrm{C}$ molar ratio are indicated in the $x$ axis.

normalized mass and elemental balances are shown in Fig. 9 for five selected solar clinkering experimental runs at $T_{\mathrm{B} 1}=1120^{\circ} \mathrm{C}, 1180^{\circ} \mathrm{C}, 1250^{\circ} \mathrm{C}$, $1265^{\circ} \mathrm{C}$, and $1285^{\circ} \mathrm{C}$. Also indicated are the nominal temperatures at the bottom $\left(T_{\mathrm{B} 1}\right)$ and top $\left(T_{\mathrm{B} 2}\right)$ of the packed bed and the irradiation time period at this temperature level. Satisfactory closing of the mass balance for $\mathrm{Zn}$ was accomplished. Diffusion of gaseous products into the insulation material presumably accounted for the missing $\mathrm{Cl}$ and $\mathrm{Pb}$, as well as molten $\mathrm{Pb}$ accumulated at the bottom of the crucible. An error source of the analysis was the inhomogeneous character of the products, especially for $\mathrm{Pb}$ as its accurate content determination in the 

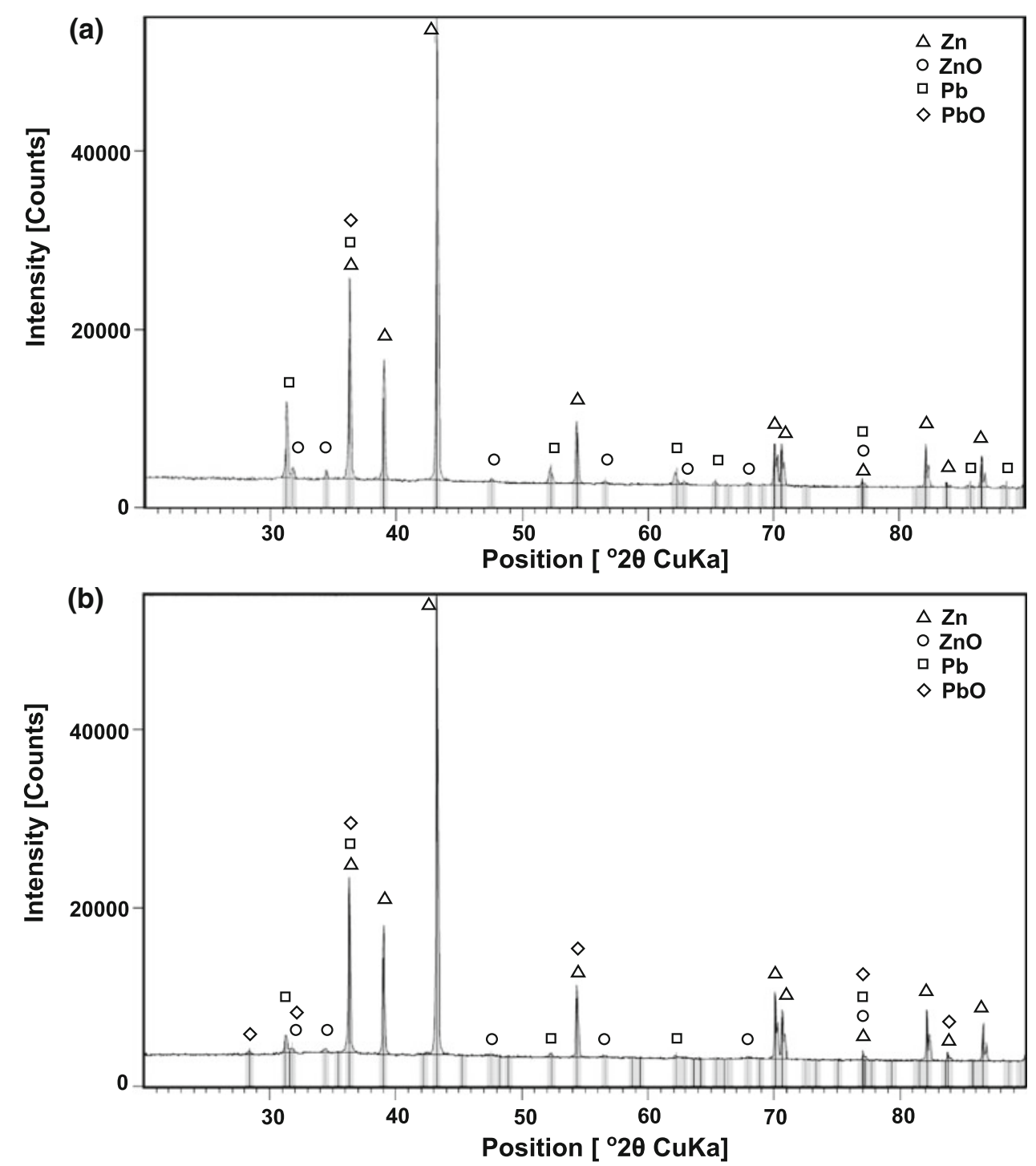

Fig. 13. XRD pattern of the condensed products for a representative run with (a) washed WOX $\left(\mathrm{ZnO}: \mathrm{C}=1: 1.25,1280^{\circ} \mathrm{C}\right)$ and $(\mathrm{b})$ solar-clinkered WOX (30 $\mathrm{min}$ at $\left.T_{\mathrm{B} 1}=1250^{\circ} \mathrm{C}, \mathrm{ZnO}: \mathrm{C}=1: 0.86,1260^{\circ} \mathrm{C}\right)$.

clinkered WOX is difficult due to the occurrence of molten $\mathrm{PbO}$ and $\mathrm{Pb}$ phases.

\section{Solar Carbothermal Reduction}

A series of 14 experimental runs with $\mathrm{ZnO}: \mathrm{C}$ molar ratios between 1:0.8 and 1:1.25 was carried out using crude, washed, and solar-clinkered WOX and commercial $\mathrm{ZnO}$. Temperatures in the range of $1110-1210^{\circ} \mathrm{C}$ and $1170-1320^{\circ} \mathrm{C}$ were reached at approximately steady state at the bottom $\left(T_{\mathrm{B} 1}\right)$ and top $\left(T_{\mathrm{B} 2}\right)$ of the packed bed, respectively. A representative run with clinkered WOX and a $\mathrm{ZnO}: \mathrm{C}$ molar ratio of 1:0.86 is shown in Fig. 10. After the first $20 \mathrm{~min}, T_{\mathrm{B} 2}=340^{\circ} \mathrm{C}$ and $T_{\mathrm{B} 1}=65^{\circ} \mathrm{C}$, and the evaporation and decomposition of volatiles occurred along with the evolution of small amounts of $\mathrm{CO}_{2}$ and $\mathrm{H}_{2} \cdot \mathrm{H}_{2}$ reached its concentration peak about 20 min later. The formation of $\mathrm{CO}$ started at
$T_{\mathrm{B} 2}=480^{\circ} \mathrm{C}$. The carbothermal reduction proceeded at high rates above $900^{\circ} \mathrm{C}$ as evidenced by the strong increase of the $\mathrm{CO}$ molar flow rate, which peaked at $0.033 \mathrm{~mol} / \mathrm{min}$ after $83 \mathrm{~min}$. This is consistent with the change in the slope of $T_{\mathrm{B} 1}$ and the subsequent decrease of the temperature gradient across the bed. $\mathrm{CO}_{2}$ represented only a small fraction of the gaseous product, indicative of its consumption via the Boudouard equilibrium (Eq. 3). The $\mathrm{Zn}$ production rate reached a maximum of $0.036 \mathrm{~mol} / \mathrm{min}$. $T_{\mathrm{B} 2}$ stabilized at $1260^{\circ} \mathrm{C}$ and $\mathrm{CO}$ evolution decreased as the reaction neared completion. Toward the end of the experimental run, the small temperature difference between $T_{\mathrm{B} 1}$ and $T_{\mathrm{B} 2}$ $\left(\sim 50^{\circ} \mathrm{C}\right)$, along with the low gas evolution, indicated complete conversion of the reactants. A visual examination of the residue revealed the presence of unreacted charcoal. Solid products were collected from the condenser, outlet pipes, and filter. The 


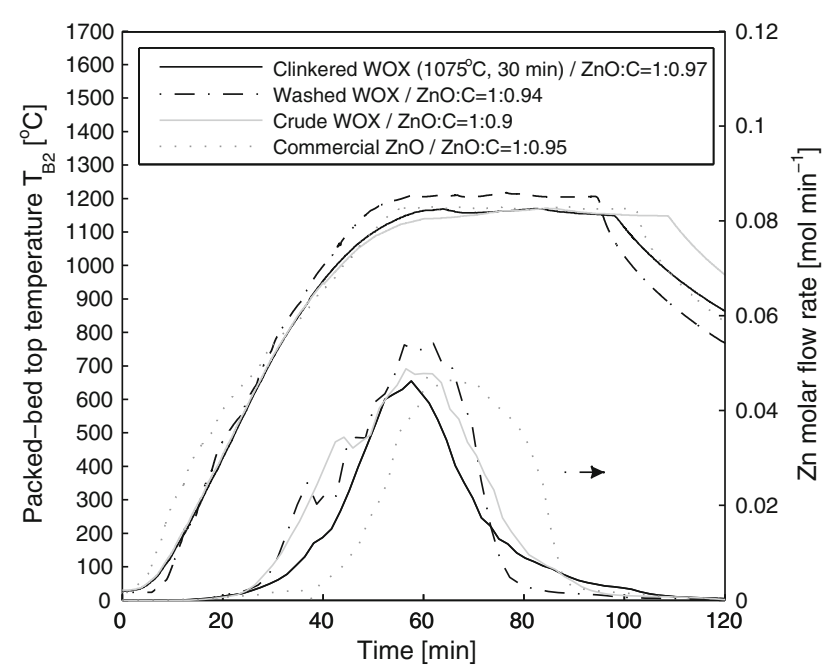

Fig. 14. Variation of the packed-bed top temperature and $\mathrm{Zn}$ production rate during the carbothermal reduction of crude, washed, and solar-clinkered WOX, and commercial $\mathrm{ZnO}$.

SEM picture of Fig. 11 shows round agglomerated particles formed upon condensation and coalescence of $\mathrm{Zn}$ vapor at short residence times.

The normalized mass balance is shown in Fig. 12 for all 14 solar carbothermal experiments. Also indicated are the nominal temperatures at the bottom $\left(T_{\mathrm{B} 1}\right)$ and top $\left(T_{\mathrm{B} 2}\right)$ of the packed bed and the $\mathrm{ZnO}$ :C molar ratio. Off-gas accounts for $\sim 18-32 \%$ of the initial mass, while the remainder was collected in the form of condensed products and reaction residue. Diffusion of condensable gas products into the insulation was partly responsible for the unclosed mass balance. This was corroborated by comparing of the total amount of $\mathrm{Zn}$ recovered in the off-gas to that calculated by integration of the production rate based on $\mathrm{CO}$ and $\mathrm{CO}_{2}$ evolution over time. Typically, 60-80\% of the $\mathrm{ZnO}$ reduced (based on the integration of $\mathrm{CO}$ and $\mathrm{CO}_{2}$ evolved) could be recovered in the off-gas system as pure metallic $\mathrm{Zn}$. However, as previously indicated, the calculation does not account for oxygen content in the reducing agent and feedstock's impurities. Condensed products from the experimental runs with washed WOX contained $\mathrm{Zn}$ in the range 85.2-92.4 wt.\%, $\mathrm{Pb}$ in the range $3.4-3.8$ wt.\%, and $\mathrm{Cl}$ in the range $0.26-$ 1.35 wt.\%. An XRD analysis, shown in Fig. 13, revealed the presence of $\mathrm{Zn}, \mathrm{ZnO}$, and $\mathrm{Pb}$ for all $\mathrm{ZnO}$ sources, apart from commercial $\mathrm{ZnO}$ that showed no $\mathrm{Pb}$ as expected. With solar-clinkered WOX as a reactant, the intensity of the $\mathrm{Pb}$ diffraction peaks was significantly lower, indicating a higher purity of $\mathrm{Zn}$. This was expected because the $\mathrm{Pb}$ content was reduced to much lower levels by solar clinkering compared to industrial washing. Pb resulted either from $\mathrm{PbO}$ vaporization and reduction with $\mathrm{CO}$ or directly from the carbothermal reduction of $\mathrm{PbO}$.

The variation of the $\mathrm{Zn}$ production rate for the carbothermal reduction of the various $\mathrm{ZnO}$ feedstock-namely crude, washed, and solar-clinkered

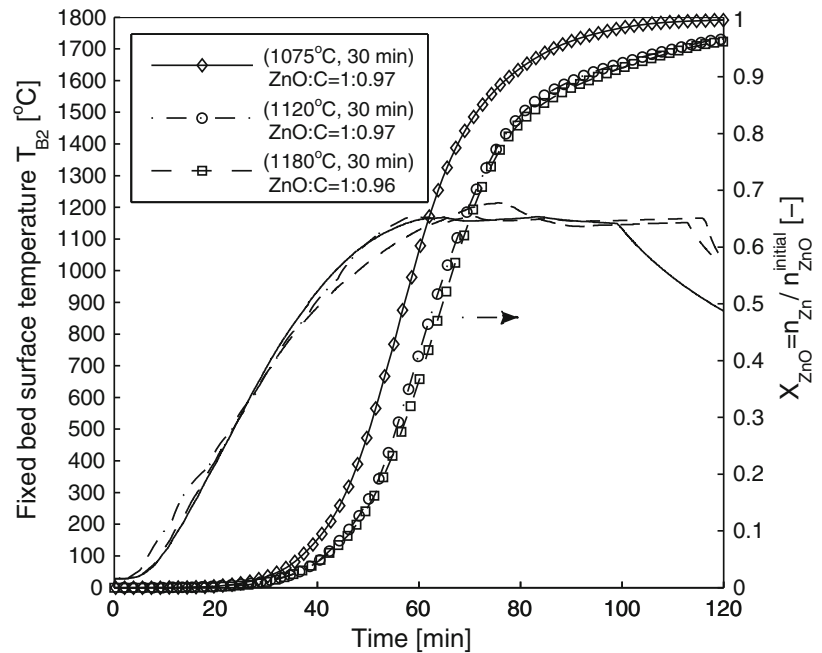

Fig. 15. Variation of temperature and chemical conversion as a function of time during the solar carbothermal reduction of three solar-clinkered WOX samples that were purified at $T_{\mathrm{B} 1}=1075^{\circ} \mathrm{C}$, $1120^{\circ} \mathrm{C}$, and $1180^{\circ} \mathrm{C}$ during $30 \mathrm{~min}$.

WOX, and for commercial $\mathrm{ZnO}-$ is shown in Fig. 14 for $\mathrm{ZnO}: \mathrm{C}$ molar ratios in the range of 1:0.9-1:0.97. Both crude and washed WOX yielded faster reduction rates compared to solar-clinkered WOX and commercial $\mathrm{ZnO}$. This is attributed to the inherently different morphology and properties of the various $\mathrm{ZnO}$ sources, affecting heat/mass transfer and intrinsic kinetics. The solar-clinkered WOX exhibited a lower specific surface area available for the solid-gas reaction (Eq. 2) due to partial sintering and melting. Note that the content of oxides other than $\mathrm{ZnO}$ (mainly $\mathrm{PbO}$ ) in the crude and washed WOX resulted in an overestimation of the $\mathrm{CO}$ and $\mathrm{CO}_{2}$ evolved from the carbothermal reduction of $\mathrm{ZnO}$ by up to $15 \%$ and $19 \%$, respectively, as calculated from the asymptotic conversions. In terms of the maximum reduction rates, crude, washed, solar-clinkered WOX, and commercial $\mathrm{ZnO}$ yielded similar values to each other.

The effect of the heat treatment temperature during solar clinkering of crude WOX on the $\mathrm{Zn}$ production rate during the carbothermal reduction was explored with three solar-clinkered WOX samples that were purified at different temperatures, namely at $T_{\mathrm{B} 1}=1075^{\circ} \mathrm{C}, 1120^{\circ} \mathrm{C}$, and $1180^{\circ} \mathrm{C}$ during $30 \mathrm{~min}$. The variation of temperature and chemical conversion as a function of time during the carbothermal reduction of these three samples is shown in Fig. 15. Comparable asymptotic conversions were obtained for all samples. Slower rates were expected at higher clinkering temperatures because of the decrease of the specific surface area due to partial sintering/melting, but this effect was not observed for the temperatures considered.

\section{CONCLUSIONS}

Solar clinkering using concentrated solar energy was proposed as an alternative cleaner route to the 
purification of WOX and experimentally demonstrated using a $10 \mathrm{~kW}_{\text {th }}$ packed-bed solar reactor. $\mathrm{Cl}$ and $\mathrm{Pb}$ contents lower than those of washed WOX $(<0.1$ wt.\%) were attained by solar clinkering of crude WOX at elevated temperatures $\left(T_{\mathrm{B} 1}>\right.$ $1265^{\circ} \mathrm{C}$ ). Depletion of $\mathrm{Pb}$ and its compounds represented a major advantage of the proposed solardriven process vis-à-vis the industrial washing process and led to higher $\mathrm{ZnO}$ contents ( 88 wt.\%) in the product. The solar-driven production of $\mathrm{Zn}$ via the carbothermal reduction of clinkered, washed, and crude WOX was experimentally demonstrated using the same packed-bed solar reactor. Beech charcoal was used as reducing agent for a $\mathrm{CO}_{2^{-}}$ neutral carbothermal process. Zn contents of about $90 \mathrm{wt} . \%$ were obtained in the condensed products. Incorporation of continuous or semicontinuous feeding of reactants and removal of products can improve product yield and thermal efficiency.

\section{REFERENCES}

1. V. Popovici (Paper presented at the 5th Global Slag Conference, Brussels, 23-24 November 2009).

2. T. Sofilic, A. Rastovcan-Mioc, S. Cerjan-Stefanovic, V. Novosel-Radovic, and M. Jenko, J. Hazard. Mater. 109, 59 (2004).

3. A.J. Xu, Q.X. Yang, B. Gustafsson, F. Wang, J.L. Li, and B. Bjorkman, J. Iron. Steel Res. Int. 17, 132 (2010).

4. J. Ruetten, SEAISI Q. J. 35, 13 (2006).

5. N.L. Piret, World Metall. Erzmet. 65, 306 (2012).

6. M.H. Morcali, O. Yucel, A. Aydin, and B. Derin, J. Min. Metall. Sect. B 48, 173 (2012).

7. N. Leclerc, E. Meux, and J.M. Lecuire, J. Hazard. Mater. 91, 257 (2002).

8. C. Caravaca, A. Cobo, and F.J. Alguacil, Resour. Conserv. Recycl. 10, 35 (1994).

9. J. Antrekowitsch and H. Antrekowitsch, JOM 53, 26 (2001).

10. B. Schaffner, W. Hoffelner, H.Y. Sun, and A. Steinfeld, Environ. Sci. Technol. 34, 4177 (2000).
11. B. Schaffner, A. Meier, D. Wuillemin, W. Hoffelner, and A. Steinfeld, Environ. Sci. Technol. 37, 165 (2003).

12. N. Menad, J.N. Ayala, F. Garcia-Carcedo, E. Ruiz-Ayucar, and A. Hernandez, Waste Manag. 23, 483 (2003).

13. C. Wieckert and A. Steinfeld, J. Sol. Energy-Trans. ASME 124, 55 (2002).

14. C.E. Guger and F.S. Manning, Metall. Trans. 2, 3083 (1971).

15. K.F. Blurton and A.F. Sammells, J. Power Sources 4, 263 (1979).

16. J.R. Goldstein and B. Koretz (Paper presented at Energy Environment Economics: 28th Intersociety Energy Conversion Engineering Conference Proceedings (Iecec-93), 1993), pp. 279-284.

17. K. Wegner, H. Ly, R. Weiss, S. Pratsinis, and A. Steinfeld, Int. J. Hydrogen Energy 31, 55 (2006).

18. R. Weiss, H. Ly, K. Wegner, S. Pratsinis, and A. Steinfeld, AIChE J. 51, 1966 (2005).

19. A. Steinfeld, Sol. Energy 78, 603 (2005).

20. A. Berman and M. Epstein, Int. J. Hydrogen Energy 25, 957 (2000).

21. E. Bilgen, M. Ducarroir, M. Foex, F. Sibieude, and F. Trombe, Int. J. Hydrogen Energy 2, 251 (1977).

22. P.G. Loutzenhiser, M.E. Galvez, I. Hischier, A. Stamatiou, A. Frei, and A. Steinfeld, Energy Fuel 23, 2832 (2009).

23. P.G. Loutzenhiser and A. Steinfeld, Int. J. Hydrogen Energy 36, 12141 (2011).

24. A. Stamatiou, P.G. Loutzenhiser, and A. Steinfeld, Chem. Mater. 22, 851 (2010)

25. J. Petrasch, P. Coray, A. Meier, M. Brack, P. Häberling, D. Wuillemin, and A. Steinfeld, J. Sol. Energy-Trans. ASME 129, 405 (2007).

26. W.T. Welford and R. Winston, High Collection Nonimaging Optics (San Diego, CA: Academic Press, 1989).

27. A. Yogev, M. Epstein, and A. Kogan, Int. J. Hydrogen Energy 23, 239 (1998).

28. C. Wieckert, A. Meier, and A. Steinfeld, J. Sol. EnergyTrans. ASME 125, 120 (2003).

29. C. Wieckert, J. Sol. Energy-Trans. ASME 127, 425 (2005).

30. S. Steinlechner, Waelz Oxide Characterization, unpublished report for Befesa (Leoben, Austria: Department of Metallurgy, Montan University, 2012).

31. S. Kräupl, U. Frommherz, and C. Wieckert, J. Sol. EnergyTrans. ASME 128, 8 (2006).

32. G. Graf, Ullmann's Encyclopedia of Industrial Chemistry, Vol. A28 (Weinheim, Germany: VCH Verlagsgesellschaft, 1996), pp. 509-530. 